\title{
PENDAMPINGAN LITERASI KRITIS NATION DAN CHARACTER BUILDING PESERTA MAGANG TEKNOLOGI ANIMASI DI NUSANTARA CULTURE ACADEMY (NCA) MALANG TAHUN 2021
}

\author{
Umi Salamah, Rokhyanto, Kingkin Puput Kinanti \\ IKIP Budi Utomo \\ umi.salamah@ budiutomomalang.ac.id, rokhyanto3@gmail.com , kinantipuput8@gmail.com
}

\begin{abstract}
The writing of this article is based on the results of serving the community which aims to strengthen the sense of love for the Indonesian nation and state so that the Millennial generation can dedicate their mastery of science and technology to the progress and welfare of the nation. By practicing critical literacy, it is hoped that participants will have strong filters and principles in receiving information on social media, so they are not easily provoked by hoax news. The target of the service is animation technology apprentices at NCA Malang batch 2. Pattern means to make a model the spirit of nationalism and the courage of the freedom fighters and millennial fighters; discuss means the intention to choose a form of struggle that is suitable for the participants in the millennial era, and implement means the intention to carry out in everyday life. The mentoring technique is done by playing games, screening of documentaries and film millennial choices, singing and living the national anthem, presenting and solving problems. To avoid the spread of Covid 19 during the pandemic, teh mentoring is carried out virtually. The results obtained are (1) the occurrence of understanding how to implement nation and character building in real life; (2) can contribute positively to the community, and (3) have the confidence to be able to develop talents to elevate local potential into phenomenal works.
\end{abstract}

Keywords: Critical literacy, spirit of nationalism, inspiring young millennial fighters, advancing Indonesia, people's welfare

\section{ANALISIS SITUASI}

Lokasi pengabdian masyarakat ini dilaksanakan di Nusantara Cultural Academy (NCA) Malang yang beralamat di Metro Residen Blok E.7 Bandulan Malang. Nusantara Cultural Academy (NCA) merupakan komunitas nirlaba yang beranggotakan para akademisi, pendidik, sosiolog, sejarawan, arkeolog, budayawan, dan pelaku budaya di Kota Malang yang melakukan riset terhadap sejarah, arkeologi, dan budaya di Indonesia dengan mengambil Malang Raya sebagai laboratoriumnya. Implementasi hasil penelitian diwujudkan dalam bentuk pengabdian kepada masyarakat berupa pendampingan ekskavasi temuan situs, pendampingan pengetahuan budaya, pendampingan, dan pelatihan transformasi budaya sesuai dengan perkembangan teknologi dan ilmu pengetahuan.
Di era pandemi covid 19, NCA menyelenggarakan pelatihan teknologi animasi secara daring. Pelatihan dilaksanakan selama satu tahun pelajaran. Peserta angkatan pertama dimulai pada 1 Februari -28 Desember 2020, diikuti sebanyak 27 peserta. Peserta terdiri atas siswa dan mahasiswa animasi dari Universitas Brawijaya, Universitas Negeri Malang, SMKN 1 Batu, SMKN 4, dan UNISMA yang memiliki latar belakang pendidikan desain grafis, teknologi informasi.

Melalui observasi pendahuluan yang dilakukan selama proses pelatihan terhadap peserta, diperoleh data bahwa pada umumnya peserta pelatihan belum memahami sepenuhnya nation an character building sehingga merasa bingung dengan informasi yang berkembang akhir-akhir ini maka cenderung membuat kegaduhan dan memiliki 
dampak yang sangat signifikan terhadap menurunnya semangat generasi milenial untuk berkarya. Mereka umumnya gamang terhadap pemberitaan-pemberitaan yang membuat mereka frustasi dan apatis. Mereka melihat banyak teman-teman yang mudah tersulut emosi dan mengikuti demo yang tidak diketahui materi yang didemokan. Ketidaktahuan esensi materi demo membuat peserta demo mudah tersulit emosi dan mengikuti komando untuk melakukan perbuatan anarkhis, padahal mereka pada umumnya tidak mengenal orang yang memberikan komando. Kericuhan demo yang melibatkan mahasiswa dan siswa di Malang dapat dilihat dalam gambar berikut ini.

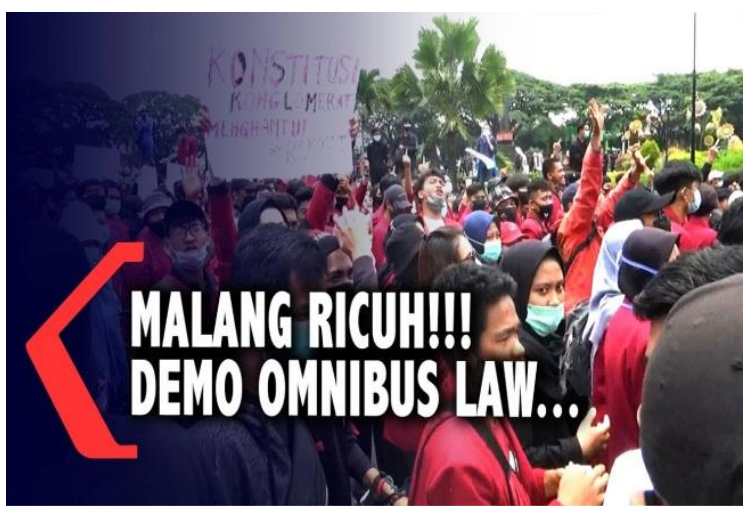

Gambar 1. Demo Omnibuslow di Malang, 08 Oktober 2020, melibatkan mahasiswa dan siswa (Sumber Kompas)

Berdasarkan hasil survei pendahuluan disimpulkan bahwa peserta magang teknologi animasi di NCA Malang memiliki kompetensi literasi kritis nation an character building yang masih rendah. Permasalahan tersebut disebabkan oleh faktor-faktor sebagai berikut (1) sebagian besar peserta lebih suka berbicara masalah cinta remaja dan mimpi menjadi orang kaya daripada masalah ideologi dan negara; (2) maraknya berita-berita hoaks di media sosial membuat mereka kurang percaya pada masa depannya dan kurang yakin negara dapat melindungi hak-haknya. Bertolak dari hasil tersebut, dilakukan kesepakatan untuk belajar literasi kritis nation and character building dengan metode Tri-M (meneladani, mendiskusikan, dan mengimplementasikan).

\section{METODE PELAKSANAAN}

Berdasarkan permasalahan yang ditemukan di lapangan, maka solusi yang ditawarkan pada program Pengabdian pada Masyarakat (IbM) adalah melakukan pendampingan literasi kritis tentang nation an character building sebagai cara untuk menguatkan jati diri sebagai warga negara Indonesia yang baik. Peserta diberikan wawasan menghargai perbedaan dan keragaman untuk menjaga kesatuan dan kerukunan, selanjutnya dijelaskan perihal spirit mencintai dan memajukan Indonesia melalui karya-karya yang sesuai dengan bidangnya sebagai bentuk tanggung jawab kepada bangsa dan negara.

Metode yang digunakan dalam pendampingan adalah metode Tri-M (Meneladani, Mendiskusikan, dan Mengimplementasikan). Metode Tri-M merupakan adaptasi dari metode pembelajaran Ki Hadjar Dewantara Tri-Ngo (ngerti (mengerti), ngroso (menghayati), nglakoni (melaksanakan/mengerjakan) (Dewantara, 1959; 2009). Pada tahap meneladani dimulai dengan mencairkan suasana keakraban, saling memperkenalkan diri yang dipandu host, selanjutnya mengenalkan kondisi geopolitik Indonesia, dan pemutaran film dokumenter. Setiap pemutaran film dilanjutkan dengan sarasehan untuk penguatan literasi kritis tentang nation and character building tentang ketokohan pelaku sejarah yang dapat diteladani oleh generasi muda. Pada pertemuan selanjutnya, diputar film-film wajib inspiratif seperti Ainun-Habibie, Batas, Trilogi Merdeka, dan film pilihan peserta yang menginspirasi generasi mileneal untuk mencintai bangsa dan negaranya. Film yang dipilih oleh peserta dilakukan berdasarkan penjaringan angket open ended, dan dipilih berdasarkan suara terbanyak. Setelah pemutaran film pilihan peserta, dilanjutkan diskusi untuk menggali 
potensi peserta yang dapat dikembangkan untuk berkontribusi positif kepada bangsa dan negara..

Untuk menghindari kejenuhan, sebelum dan setelah pemutaran film diselingi dengan permainan/game, quis, dan cerita kegiatan di rumah/di lingkungan masingmasing peserta selama pendampingan. Acara selalu diawali dengan menyanyikan lagu Indonesia Raya dan ditutup dengan menyanyikan lagu-lagu wajib nasional. Tujuannya untuk meguatkan penghayatan rasa cinta dan tanggung jawab sebagai anak bangsa kepada negara. Pada tahap implementasi, diawali dengan refleksi dengan membandingkan spirit mencintai bangsa generasi muda zaman dulu dan sekarang, Generasi muda luar negeri dan generasi Indonesia, dan peran diri peserta dengan pemuda lain. Hasil yang diharapkan terjadinya pemahaman terhadap implementasi nation an character building, sehingga para peserta memiliki sikap positif, tangguh, toleransi, dan banggga menjadi generasi penerus bangsa Indonesia. Keberhasilan pendampingan diukur dari hasil quis, esai yang ditulis berdasarkan hasil refleksi selama pendampingan, kesan-pesan dan antusias selama mengikuti sosialisasi.

Materi sosialisai dipilah menjadi tiga bagian, yaitu (1) film dokumenter tentang Sumpah Pemuda, Pejambon (Sidang persiapan kemerdekaan), dan Detik-detik Pembacaan Proklamasi Indonesia; (2) Fim inspiratif antara lain, film Ainun-Habibie, King, Minggu Pagi di Victoria Park, Denias, Laskar Pelangi, Trilogi Merdeka, dan Film pilihan Peserta. Berdasarkan angket, film pilihan antara lain Denias, The Girl Who Leapt Through Time (animasi dari Jepang), The Wind Rises (Jepang) dan (3) Power point tentang geopolitik Indonesia, wawasan tentang nation an character building; dan Ideologi Pancasila. Dipilihnya materi-materi itu karena materi-materi tersebut memiliki nilai-nilai pendidikan nasionalisme/nation and character building dan etos kerja yang pantang menyerah dalam memperjuangkan dan memajukan negaranya melalui bidang yang ditekuninya.

Film dokumenter Sumpah Pemuda menggambarkan keberanian dan antusias sekelompok pemuda yang mencari jati diri bangsa dan negaranya sebagai embrio mencapai

kemerdekaan (https://www.youtube.com/watch?v=QbhkHG1 7Eis). Film dokumenter Sidang Persiapan Keperdekaan menggambarkan semangat kebersamaan, antusias, dan sikap arif dalam menghargai perbedaan pendapat, suku, ras, dan agama untuk tujuan yang lebih besar, yaitu mencapai kemerdekaan. Film dokumenter Detik-detik Proklamasi menggambarkan suasana heroik dan kebersamaan dalam mencintai kemerdekaan (https://www.youtube.com/watch?v= iegHwX_jrJ4). Ketiga film tersebut menggambarkan spirit keberanian, kebersamaan, dan kesatuan dlam memperjuangkan kemerdekaan.

Film Ainun-Habibi, meski dikenal sebagai film romansa antara Habibie dan Ainun, namun dalam film ini juga digambarkan sosok Habibie yang tegas dalam menomorsatukan kepentingan negara. Menolak suap, sampai memilih kembali ke Indonesia meski telah mapan di negeri orang. Kerja keras sampai larut tanpa mengeluh juga dilakukan Habibie demi kemajuan negara (https://www.youtube. com/watch?v=7uV166LCp10). Film King mengisahkan perjuangan Guntur, seorang anak yang mengidolakan Liem Swie King, juara dunia bulu tangkis. Ia berjuang dan berlatih keras demi mendapatkan beasiswa bulutangkis demi cita-citanya menjadi juara dunia untuk mengharumkan nama Indonesia seperti Liem Swie King (https://www.youtube.com/watch?v=TfqBzo c0oM)

Film Minggu Pagi di Victoria Park ini mengisahkan nasib tenaga kerja wanita (TKW) Indonesia di Hong Kong. Judulnya yang merujuk pada tradisi para TKW Indonesia yang sering berkumpul di Victoria Park, berbagi cerita mengenai kehidupannya 
masing-masing. Mereka curhat tentang seringnya mendapatkan perlakuan diskriminatif dari negaranya sendiri. Menyaksikan film ini, penonton bisa merenungkan banyak hal, termasuk fakta bahwa para TKW berada dalam kondisi yang tidak memiliki pilihan lain kecuali menjalankan hidup mereka di negara orang, dan bagaimana mereka menjadi salah satu sumber devisa negara kita. Film Denias, diangkat dari kisah nyata anak Papua yang menceritakan Denias, anak suku pedalaman Papua yang ingin mendapatkan pendidikan yang layak. Dalam film ini peserta disuguhkan dengan pemandangan Papua yang indah yang menunjukkan betapa indah dan kayanya Indonesia. Film Laskar Pelangi menceritakan persahabatan anak-anak Belitong yang walaupun hidup di tempat yang terpencil tetapi mereka pantang menyerah untuk belajar dan bersemangat dalam hidup. Film trilogi Merah Putih berkisah tentang perjuangan melawan tentara Belanda pada tahun 1947. Tokohnya bernama Amir, Tomas,, Soerono, dan Marius merupakan lima kadet (calon perwira) yang mengikuti latihan militer di sebuah Barak Bantir di Semarang Jawa Tengah. Masingmasing mempunyai latar belakang, suku, dan agama yang berbeda. Suatu ketika, kamp tempat mereka berlatih diserang tentara Belanda, mereka berhasil lolos dan bergabung dengan pasukan gerilya di pedalaman Jawa. Di sana, mereka menemukan strategi untuk mengalahkan pasukan Belanda. Film-film di atas memiliki spirit perjuangan yang dapat digunakan untuk untuk membangkitkan rasa nasionalisme.

Film animasi The Girl Who Leapt Through Time dari Jepang yang berarti "Wanita yang Melompati Waktu" adalah sebuah film besutan Mamoru Hosoda yang menceritakan seorang gadis bernama Makoto Konno yang akan lulus SMA. Di tengah kegalauannya dalam menentukan masa depannya, ia menemukan sebuah kekuatan yang mengubah hidupnya. Ia bisa melompati waktu. Kekuatan itupun ia gunakan dalam kehidupannya, namun bukan dengan tanpa konskuensi. Film ini menyadarkan kita tentang pentingnya menghargai waktu, serta cara mensyukuri setiap keadaan yang kita terima saat kini. Dengan menonton film ini, penonton akan menyadari untuk menghargai setiap langkah dan waktu yang ditempuh (https://www.youtube.com/watch?v=AwIvM hfUa6I). Fim The Wind Rises atau lebih dikenal sebagai Kaze Tachinu, merupakan film garapan Hayao Miyazaki. Film ini mengisahkan seorang pria bernama Jirou Horikoshi yang hidup penuh mimpi (citacita), yakni cita-cita untuk terbang, serta citacita untuk membawa dunia ke arah yang lebih baik. Film ini diangkat dari kisah orang nyata, yakni Jirou Horikoshi, yang berhasil membangun pesawat Mitsubishi A6M Zero Fighter, pesawat terkenal dalam sejarah penerbangan Jepang. Meski melalui berbagai peristiwa kehilangan, musibah, asmara, dan perang, Jirou tetap berjuang mengejar citacita/mimpinya agar bisa tercapai (https://www.youtube.com/watch?v=2QFBZ gAZx7g).

\section{HASIL DAN PEMBAHASAN}

Berdasarkan data yang diperoleh selama pelatihan, berikut ini dijelaskan proses dan hasil pelaksanaan pendampingan wawasan kebangsaan dan ideologi Pancasila terhadap peserta magang teknologi animasi di NCA Malang. Pendampingan dilaksanakan secara virtual melalui zoom meeting dan action di rumah dan lingkungan masing-masing peserta. Hal ini mengacu pada peraturan pemerintah tentang protokol kesehatan (Prokes) pencegahan covid 19 di masa pandemi. Berdasarkan metode Tri-M, model pelaksanaan sosialsasi digambarkan sebagai berikut: 

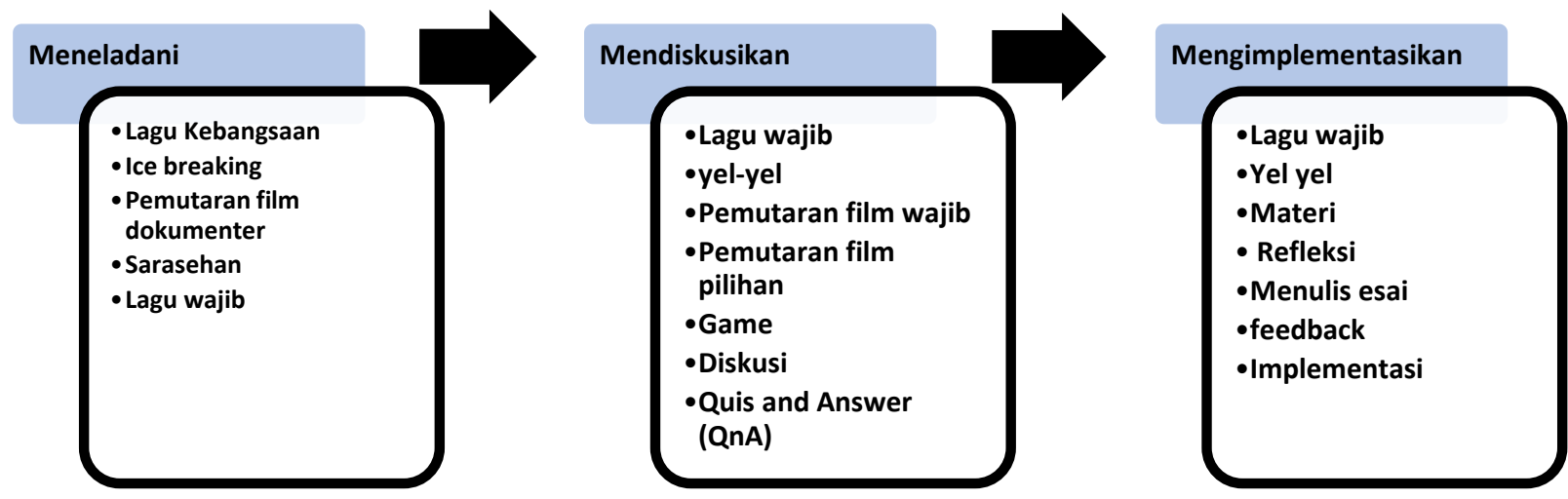

Gambar 2: Model Metode Tri-M Pendampingan Virtual Literasi Kritis Nation and Charakter Bulding

Berdasarkan gambar tersebut dapat dijelaskan sebagai berikut:

1. Pada tahap Meneladani, dibuka dengan menyanyikan lagu Indonesia Raya. Kemudian untuk mencairkan suasana, host memandu dengan yel-yel lalu perkenalan peserta disertai dengan humor. Pada tahap ini motivasi dan anekdot disampaikan dengan humor. Setelah itu, disampaikan pemutaran film dokumenter sejarah Sumpah Pemuda, Pejambon, dan Detik-detik Proklamasi Kemerdekaan. Tujuannya untuk memantik spirit mencintai dan menjaga kemerdekaan sebagaimana yang dicitacitakan dalam Teks Sumpah Pemuda dan Pembukaan dan batang tubuh UUD 1945. Selanjutnya disampaikan materi 1 wawasan kebangsaan, dilanjutkan tanya jawab, berbagi cerita, menyampaikan kasus, dan mencari solusi secara kritis analitis. Kegiatan ini ditutup dengan penugasan mencari film mileneal pilihan peserta yang akan diputar pada pertemuan selanjutnya.

2. Pada Tahap Mendiskusikan, untuk membuat suasana zoom virtual menjadi antusias, dilakukan permainan game. Peserta dibagi ke dalam kelompok untuk melakukan game. Dari 27 peserta dibagi ke dalam tiga kelompok, yaitu kelompok merah putih, kelompok bhinneka tunggal ika, dan kelompok gotong royong. Game pertama tebak lagu wajib nasional, kedua tebak nama tokoh sejarah, dan ke tiga tebak nama tokoh inspiratif mileneal. Pada pertemuan berikutnya, game bervariasi yaitu peragaan tokoh, tebak peta wilayah NKRI, dan lainnya. Setelah itu diputar film wajib, antara lain Ainun-Habibi, dilanjutkan dengan film pilihan peserta. Setelah itu dilakukan diskusi dan tanya jawab, untuk menguatkan spirit National and Character Building. Kegiatan ditutup dengan quis dan penugasan untuk melakukan hal-hal yang berkaitan dengan implementasi National and Character Building di rumah.

3. Pada tahap Mengimplementasikan dilakukan sarasehan virtual dengan laporan aksi implementasi National and Character Building di rumah dan di lingkunganya, dilanjutkan dengan sarasehan peneguhan nilai-nilai ideologi Pancasila dan pentingnya penguatan spirit National and Character Building. Kemudian, peserta diminta menulis dan membacakan pesan kesan, selanjutnya diminta untuk memberikan feedback. Kegiatan ditutup dengan penulisan esai tentang National and Character Building dan penerapannya dalam kehidupan sehari-hari.

Berdasarkan hasil pendampingan, pemahaman terhadap esensi literasi kritis National and Character Building 
ditunjukkan dengan hasil quis dan esai tentang pentingnya pemahaman National and Character Building bagi generasi milenial. Hasil quis menunjukkan rata-rata peserta memperoleh skor 88 , skor tertinggi 100 , dan terendah 86. Hal itu menunjukkan keberhasilan pendampingan pemahaman wawasan kebangsaan dan ideologi Pancasila. Selain itu, dari hasil analisis hasil penulisan esai diperoleh gambaran, semua peserta memiliki cara yang unik dan berbeda-beda untuk mencintai bangsa dan negara melalui kualitas karya dan mengejawantahkan spirit National and Character Building dalam kehidupan sehari-hari. Di akhir acara pendampingan, semua peserta menunjukkan sikap sebagai generasi mileneal yang antusias, dapat mengekspresikan wujud terima kasih kepada para nara sumber yang telah memberikan pendampingan literasi kritis National and Character Building. Sikap terhadap pemahamannya ditunjukkan dari antusias mengikuti pendampingan, tanya-jawab, semangat menyanyikan lagu kebangsaan dan lagu-lagu wajib nasional, kesan pesan, dan esai yang ditulis oleh peserta magang. Selain itu, adanya keinginan peserta magang untuk membuat animasi tokoh-tokoh sejarah, toponimi, dan membuat logo produk marchendise bertema tokoh sejarah, spirit National and Character Building.

\section{KESIMPULAN}

Berdasarkan hasil dan pembahasan dapat disimpulkan bahwa pelaksanaan pendampingan secara virtual dengan zoom meeting tidak menyurutkan semangat dan antusias peserta dalam mengikuti pendampingan, karena dikemas dengan menggunakan dengan metode Tri-M, dan materi sesuai dengan kebutuhan kekinian mileneal. Berdasarkan strategi dan metode tersebut diperoleh hasil pemahaman peserta yang sangat tinggi terhadap literasi kritis National and Character Building sebagai cara mengenal, menjaga, dan memajukan jati diri bangsa Indonesia sebagai bangsa yang besar dan bermartabat, baik di kancah nasional maupun internasional.

Berdasarkan hasil yang dicapai, disarankan agar di sekolah, di kampus, dan di lembaga-lambaga nonformal dilakukan penanaman literasi kritis National and Character Building untuk menguatkan spirit kebangsaan Indonesia kepada generasi penerus bangsa agar semangat nasionalisme tidak mudah diruntuhkan kepentingan politik maupun kepentingan asing.

\section{DAFTAR PUSTAKA}

Arsyad, Azhar. 2011. Strategi dan Implementasi Pendidikan Karakter Bangsa di Perguruan Tinggi, Makalah, Direktorat Perguruan Tinggi Agama Islam, Kementrian Agama RI. Jakarta

Anderson, Bennedict. 1991. Imagined Community: Reflections On The Origin And Spread of Nationalism. London: Verso.

Arjoso, Amin . 2000. Pancasila Dasar Falsafah Negara. Yayasan Kepada Bangsaku. Jakarta.

Basari, Hasani/Bernhard Dahm. 1987. Soekarno dan Perjuangan Kemerdekaan. Jakarta: L P3ES.J udul asli : Soekarno and the struggle for Indonesia

Dahl, Robert A. 1982. Dillemas of Pluralist Democracy: Autonomy vs Control.Yale: Yale Universiry Press.

Dewantara, Ki Hadjar. 1959. Bagian Pertama: Pendidikan, Cetakan Pertama, Cetakan ke-3 (2009). Yogyakarta: MLPTS, 2004.

Dewantara, Ki Hadjar. 2009. Мепији Manusi Merdeka. Yogyakarta: Leutika.

Chautard, Sophie. 2009. La Geopolitique. 2e edition. Studyrama.

G. Ó Tuathail. 1996. Critical Geopolitics: The Politics of Writing Global Space. Minneapolis. University of Minnesota 
Press (Volume 6 in the Borderlines series) and London: Routledge.

Gonggong, Anhar. 2002. dalam Diskusi Terbatas, Perspehtif Sejarah atas Demokrasi Indonesia, 1I September 2002, di Bappenas oleh Direktorat Politik, Komunikasi dan Informasi.

Gunawan, Heri. 2012. Pendidikan Karakter Konsep dan Implementasi. Bandung: Alfabet

Hadi, 2010. Nation and Character Building Melalui pemahaman Wawasan Kebangsaan, Jakarta: Direktorat Politik, Komunikasi, dan Informasi, Bapennas.

https://www.youtube.com/watch?v= iegHwX_jrJ4 (Film Persiapan Kemerdekaan RI)

https://www.youtube. com/watch?v=7uV166LCp10 (Film Aiun Habibie)

https://www.youtube.com/watch?v=TfqBzo c0oM (Film King)

https://www.youtube.com/watch?v=ZPrcsAP $\underline{\mathrm{h} 4 \mathrm{nA}}$ (Film Minggu Pagi di Victoria Park)

https://www.youtube.com/watch?v=AwIvMh fUa6I (Film The Girl Who Leapt Through Time)

https://www.youtube.com/watch?v=2QFBZg AZx7g (The Wind Rises)

Lemhannas RI. 2012. Geostrategi dan Ketahanan Nasional. Jakarta.

Mumford, Andrew. 2013. Proxy Warfare. Polity Press. Cambridge.

Soekarno, Ir. 2012. Susunlah Pertahanan Nasional Bersendikan Karakteristik Bangsa - Amanat Presiden Soekarno pada Peresmian Lembaga Pertahanan Nasional di Istana Negara, tanggal $20 \mathrm{Mei} 1965$. Jakarta.
Soepandji, Budi Susilo 2014. Membangun Pondasi Dasar Nasionalisme, Makalah Gubernur Lemhannas RI pada Indonesian Fellowship Youth Camp 2012, tanggal 28 November 2014.

Linz, JuanJ . dan Alfred Stepan. 2001. Mendefnisikan dan Membangun Demokrasi dalam Menjauhi Demokrasi Kaum Penjajah, Ikrar Nusa Bhakti dan Riza Sihbudi (ed.). Bandung: Mizan.

Pusat Kurikulum Balitbang Kemdiknas. 2009. Pengembangan dan Pendidikan Budaya \& Karakter Bangsa: Pedoman Sekolah, Jakarta: Puskur Balitbang Kemdiknas.

Sasongko, Yakob Arfin Tyas, Editor Mikhael. Tantangan di Masa Depan dan Upaya Merawat Ideologi Pancasila. Kompas. : https://nasional.kompas.com/read/2 020/07/27/16572881/tantangan-dimasa-depan-dan-upaya-merawatideologi-pancasila?page $=$ all

Sudarsono, Juwono, (Ed.). 1981. Pembangunan Politik dan Perubahan Politik. Jakarta:Gramedia.

Swasono, Sri Edi dan Fauzie Ridjal. 1992. Mohammad Hatta; beberapa Pokok pihiran. Jakarta: UI-Press

Umi Salamah -Pendampingan Literasi Kritis $\mathcal{N a t i o n}$ dan Character Building Peserta Magang Teknologi Animasi Di 